\title{
A more logical approach to asthma
}

\author{
MARTIN R. HETZEL \\ M.D., M.R.C.P. \\ Whittington and University College Hospitals, London
}

\section{Introduction}

Asthma continues to stimulate a wide range of research and an article of this length cannot hope even to give an overview of recent advances in the subject. While laboratory orientated research has produced some exciting advances, for example in the elaboration of the leukotrienes and the search for new drugs which might inhibit them (Editorial, 1982), the most useful progress, from the patient's point of view, has been achieved by much simpler studies. These have reviewed our approach to the management of asthma by better monitoring techniques and better exploitation of already wellestablished drugs. In this article, I would like to adopt a very clinical approach and review work which has lead to better treatment for asthma patients today.

\section{Peak flow monitoring and rhythms}

Many asthmatics have little awareness of the severity of their asthma (Rubinfeld and Pain, 1976) and many, apparently unexpected, asthma deaths can be attributed to a failure adequately to assess their severity (Grant, 1968; Cochrane and Clark, 1975; Editorial, 1975; Stark, 1972). These observations have lead to the gradual acceptance of peak flow monitoring (e.g. with measurement of peak flow rate every $4 \mathrm{hr}$ during the waking day) in hospital practice and in the home. It has been shown that patients can keep their own peak expiratory flow rate (PEFR) records satisfactorily after minimal tuition (Hetzel, Williams and Shakespeare, 1979) and this is easily recorded with the cheap mini-Wright meter (Wright, 1978),

This approach has lead to the recognition of distinct patterns of PEFR records. Turner-Warwick (1977) has suggested that classifying patients by PEFR pattern may be more useful than traditional categories of extrinsic and intrinsic asthma. She describes three main patterns.

The 'brittle asthmatic'. These show a chaotic pattern of PEFR readings which can fall precipi- tously over a few minutes. These patients show marked reversibility after aerosol bronchodilator drugs, but the effect is short lived. This pattern identifies a group of patients with very labile asthma who genuinely need frequent treatment; perhaps even to take beta ${ }_{2}$ stimulants by aerosol every $2 \mathrm{hr}$ during the waking day, but are liable to be labelled as 'aerosol abusers'. Like the 'morning dip' pattern (vide infra), these patients are sometimes difficult to control and may be at increased risk of sudden death.

An 'irreversible' group. These initially appear not to be asthmatic, but prolonged monitoring identifies a reversible element. Several sub-groups are described. Some patients with a flat PEFR record will, nevertheless, show improvement after a few days regular inhalation of anticholinergic agents. Others show a persistently low PEFR and forced expiratory volume in 1 second $\left(F E V_{1}\right)$, but gradual improvement in the vital capacity (VC), suggesting reversible obstruction in the small airways. The 'drifter' shows very gradual improvement in PEFR over a week or more of intensive treatment. The importance of PEFR monitoring in these cases is that the continual record enables these positive trends to be identified so that trials of bronchodilator and steroid therapy are continued long enough to produce benefit. Improvement may be small; perhaps from $100-2001 / \mathrm{min}$, but the symptomatic benefit to these patients, who will otherwise be labelled as chronic bronchitics and receive little treatment, is considerable.

The 'morning dip' pattern. These patients show a regular fall in PEFR in the early morning, usually associated with a history of wheezing in the morning or night. The observation that asthma is often worse at night can be traced back at least to the 12th century in the writings of Moses Maimonides, Body Physician to Saladin (Muntner, 1963) and has subsequently been described by several famous physicians (Willis, 1679; Laennec, 1827; Trousseau, 1868). Only with the introduction of PEFR monitoring, however, has it been realized that patients may be well, with near normal lung function tests during the day and yet have severe airways obstruction at 
night; thus the severity of their asthma may be seriously underestimated and under treated.

The precise aetiology of the 'morning dip' remains uncertain (Editorial, 1981a). It is seen in both intrinsic and extrinsic, atopic asthmatics (Clark and Hetzel, 1977; Connolly, 1979) and persists in asthmatics living in allergen free chambers (Reinberg et al., 1970); thus allergy to the house dust mite or other allergens in bedding at night is not responsible. It is not caused by the sleeping posture (Clark and Hetzel, 1977) and cannot be attributed to the effect of sleep (Kales et al., 1968; Hetzel and Clark, 1979a). It clearly results from a circadian rhythm (or rhythms), because it can be shown to alter its phase in asthma patients who go on shift work and rapid changes of shift will reduce the amplitude of variation in PEFR (Clark and Hetzel, 1977; Hetzel and Clark, 1979b). It was therefore suggested that it might result from the circadian fall in plasma cortisol at night, since this would be expected to have a delayed effect on the airways. Soutar et al. (1975) have, however, shown that, when the natural cortisol rhythm is obliterated by a continuous infusion of cortisol, this does not affect the rhythm in PEFR.

Any proposed mechanism for nocturnal asthma must take account of the fact that a similar rhythm in PEFR can be demonstrated in normal subjects (Hetzel and Clark, 1980) although the amplitude (about $8 \%$ of mean daily PEFR) is much lower than in asthmatics ( $>20 \%$ of mean daily PEFR). Soutar, Carruthers and Pickering (1977) found some correlation between the nocturnal fall in PEFR and urinary excretion of adrenaline and noradrenaline. Further evidence that rhythms in circulating catecholamines are responsible comes from the work of Barnes et al. (1980) who showed correlations between nocturnal falls in PEFR and plasma adrenaline and cyclic AMP. Moreover, since a nocturnal rise in plasma histamine was seen in asthmatics but not in normals, they postulate a 'permissive' action on the mast cells of the nocturnal fall in adrenaline, resulting in release of histamine and possibly other mediators. These observations only show, however, that these various rhythmic factors are in phase with one another; as are many other biological rhythms such as core temperature and electrolyte excretion. To prove that the catecholamines drive the PEFR rhythm would require the demonstration that altering the catecholamine rhythm produced an appropriate change in the PEFR rhythm.

The nadir of the rhythm in body temperature (which has an amplitude of about $0.5^{\circ} \mathrm{C}$ ) also shows a close relationship to the nocturnal fall in PEFR (Hetzel and Clark, 1979b). In view of the relationships between airway cooling and exercise induced asthma (Strauss et al., 1977), Chen and Chai (1982) have suggested that the fall in body temperature may be sufficient to cause nocturnal asthma and have्๊ demonstrated improvement in nocturnal asthm艿 from breathing warm humidified air.

Although nocturnal exposure to allergens is not $\frac{c}{\mathrm{a}}$ viable explanation, allergen exposure, particularly i $\overrightarrow{\vec{m}^{*}}$ bronchial challenge tests, can induce increased bron:chial lability which results in greater sensitivity to the unknown biological clock and recurrent nocturna尔 asthma is then seen for several nights after challeng (Davies, Green and Schofield, 1976; Newman Taylof et al., 1979). Moreover, bronchial sensitivity tôn challenge with histamine (De Vries et al., 1962) acetylcholine (Reinberg et al., 1974) and inhaled allergens (Gervais et al., 1977) is increased at night $\vec{\omega}$

Finally, mucociliary clearance has been shown to decrease at night, using a gamma camera to count the removal of inhaled ${ }^{99} \mathrm{Tc}^{\mathrm{m}}$-tagged polystyrene particles (Bateman, Pavia and Clarke, 1978a). This is attrie buted to the effect of sleep, however, rather than circadian rhythm (Bateman et al., 1978b).

Thus a number of different rhythmic factors contribute to the PEFR rhythm. It appears that the amplitude of the rhythm reflects the degree of bronchial liability and this is the most crucial point $\vec{t}$ for the clinician. Ryan et al. (1982) have shown a good correlation between the fall in PEFR in the night and the threshold sensitivity to bronchial challenge with histamine. A study of asthma morfiglo ity at Brompton Hospital (Hetzel, Clark and Branth waite, 1977a) showed severe 'morning dips' with faif of $>50 \%$ of the highest daily PEFR preceding episodes of sudden ventilatory arrest in asthmatice who were thought not to be in any danger. At leasf one paper has identified similar degrees of 'morning dipping' in patients who were recording PEFR a home prior to sudden death outside hospital (Bate 3 man and Clark, 1979). Thus severe 'morning dipping? is an important clinical observation and these patients need careful assessment.

Interpretation of PEFR records is, however, subjective process and there is a danger of overi interpretation in patients with persistently low read? ings where the slight variation between readings dues to instrument accuracy and the patient's technique may produce sufficient biological noise to be misine terpreted as a significant pattern. Attempts have been made to describe further refinements of the 'morning dip' pattern (Connolly, 1979), but their usefulness is debatable. Although pattern recognition is subjec $\cong$ tive, agreement between panels of observers is good (Venables et al., 1983). Computer programs have been used to remove effects of observer bias. Cosinof analysis looks for the goodness of fit of the raw data to a 24-hr cycle and estimates amplitude and phase of the rhythm. This confirms clinical impressions thas greatest amplitudes are seen in asthma (Hetzel and Clark, 1980) and similar amplitudes are seen ino 
normals and chronic bronchitics (Dawkins and Muers, 1981). Asthmatic children have lower amplitudes (Johnston, Anderson and Patel, 1983) than asthmatic adults. Cusum analysis has been used in attempts to identify deterioration in the variation in PEFR and avoid severe attacks by earlier revision of treatment, but this technique has not proved useful (Mitchell, Collins and Morley, 1980). Thus, simple observation of the raw PEFR data is the best method of monitoring PEFR, provided over-interpretation of biological noise is avoided.

PEFR monitoring is of considerable value in the diagnosis of occupational asthma which is now a compensatable disease for some categories of occupational allergen (Editorial, 1981b). Bronchial challenge to these agents is technically difficult, potentially dangerous in inexperienced hands, and may be misleading if the correct allergen has not been identified from the history. Moreover, patients' airways obstruction may be too severe for bronchial challenge to be possible. Collection of a 'work record' of PEFR during exposure to the patient's normal work (Burge, O'Brien and Harries, 1979) is therefore the best way of establishing that the patient's work causes his asthma and further testing may not be necessary.

\section{Frequency and route of drug treatment for asthma}

Although no major advances have been made in development of drugs for asthma since the introduction of the inhaled steroids, the last few years have seen considerable interest in the ways in which existing drugs are used, with particular reference to more regular, prophylactic, treatment and the increased use of inhalational therapy. The introduction of sodium cromoglycate (SCG) and subsequent trials in adults (Brompton/MRC, 1972; Northern General Hospital/Brompton/MRC, 1976) and children (Silverman et al., 1972) was a major milestone in the management of asthma as it introduced the concept that a safe drug could be regularly given by inhalation as prophylaxis against asthma attacks. Subsequent attempts to develop other drugs like SCG have drawn into question its presumed action by prevention of mast cell degranulation (Stokes and Morley, 1981) and many chest physicians now regard sodium cromoglycate as a rather weak drug, which is a pity in view of its excellent safety record.

It has now become clear that aerosol preparations of beta ${ }_{2}$ stimulant drugs (salbutamol, terbutaline, orciprenaline) can be used in the same way as regular prophylactic treatment (Clark, 1971) and are more potent than SCG. It is difficult to dissociate a true protective, 'SCG-like' action from the direct effect of sustained bronchodilatation (Hetzel, Batten and Clark, 1977b) but in vitro studies of mediator release by allergen challenge of passively sensitized human chopped lung (Assem and Schild, 1969) shows that sympathomimetic drugs are many times more potent than cromoglycate in prevention of histamine release. Moreover, it has been shown that, when aerosol salbutamol is taken on a regular, as opposed to a symptomatic basis, control of symptoms improves, but total aerosol consumption is not much greater (Shepherd, Hetzel and Clark, 1981).

It is now generally accepted that aerosol beta ${ }_{2}$ drugs were wrongly incriminated in the epidemic of asthma deaths in the 1960s (Speizer et al., 1968; Inman and Adelstein, 1969) and that the real cause of these deaths was inadequate assessment of these attacks and the masking effect of partial response to these drugs (Grant, 1968; Fraser et al., 1971). Unfortunately, many doctors are still frightened of aerosol beta drugs, as a result of which their patients, if they fail to respond to cromoglycate, may be treated with steroids unnecessarily. Many studies have now confirmed the safety of these drugs and have shown that they are much more effective, with much less side effect (tremor, tachycardia) when given by the aerosol as opposed to the oral route (Spiro et al., 1975; Hetzel and Clark, 1976). This is not surprising since much smaller doses of these drugs are needed for direct access to the beta ${ }_{2}$ receptors and blood levels of labelled salbutamol are virtually undetectable after inhalation (Walker $e t$ al., 1972). Concern for the safety of the freon propellants in these aerosols is also unjustified since they have a very short half-life (Patterson, Sudlow and Walker, 1971).

Having accepted the value of inhalational therapy, effective inhalation is crucial to success. Between 8 and $30 \%$ of patients have serious deficiencies in their inhalation technique and cannot co-ordinate inhalation with actuation of the pressurized aerosol (Saunders, 1965; Coady, Davies and Barnes, 1976a; Patterson and Crompton, 1976). Attempts have been made to overcome this with pressurized aerosols which are actuated by inhalation (Coady et al., 1976b). Simpler devices incorporate a tube between the aerosol jet and the patient's oropharynx so that particle velocity is slowed down and precise coordination becomes less important (Moren, 1978). Bloomfield, Winsey and Crompton (1979) showed that inhalation could be delayed for 2 seconds without loss of effectiveness with this device and Godden and Crompton (1981) demonstrated good results in clinical trials. The Nebuhaler (Astra) incorporates a very large tube with an inspiratory valve at the mouthpiece end, so that the aerosol is contained until the patient inhales it, but this device is too cumbersome for use outside the home. The most effective device for the majority of patients is probably the dry powder (Rotahaler, Allen and Hanbury's) system since this is relatively simple, yet truly breath actuated. There is some loss 
of potency in comparison with the pressurized aerosol (Duncan et al., 1977; Hetzel and Clark, 1977) but this is easily compensated by incorporating a higher dose in the rotahaler capsules $(200-400 \mu \mathrm{g}$ in capsules versus $100 \mu \mathrm{g}$ per shot in the pressurized aerosol). It is often effective in children, many of whom can manage it from about 3 years old. Nevertheless, the original design was complicated and some patients could not assemble it. More recent modifications are better, but there is still room for improvement.

Amongst the converted, there is now increasing interest in further exploitation of inhalational therapy by using higher doses for those patients who are less responsive to these drugs. Domicilary inhalation of sympathomimetic drugs by wet nebulization, either from an oxygen cylinder or from an electric pump delivering compressed air, can be effective in such patients (Connellan and Wilson, 1978). A similar effect is more cheaply obtained, however, by high doses from the conventional pressurized aerosol; perhaps with further improvement of inhalational efficiency with devices such as the tube spacer. Thus Prior, Nowell and Cochrane (1982) showed significant improvement in patients with poorly reversible airways obstruction when using terbutaline in a dose of $4 \mathrm{mg}$ four times a day by both wet nebulization and a specially prepared high dose pressurized aerosol (1 mg per shot). Only $10 \%$ of a pressurized aerosol dose is actually inhaled (Neuman et al., 1980) and only some $12 \%$ of drug delivered by wet nebulization reaches the airways. Accepting these difficulties in studying truly comparable doses of sympathomimetics by these two routes, Anderson, Goude and Peake (1982) compared $4.8 \mathrm{mg}$ of salbutamol by nebulizer and pressurized aerosol. As with the study of Prior et al. (1982), salbutamol was equally effective by either route and well tolerated.

Similar developments have taken place in the use of the inhaled steroids. The value of inhaled beclomethasone dipropionate $\left(\right.$ Becotide $^{\circledR}$ ) is well established in reducing requirements for oral steroids (BTTA, 1976) or avoiding their use altogether, and this is particularly important in avoiding growth suppression in children. It has now become apparent that higher doses can be given with little or no adrenal suppression so that some borderline patients who still need low doses of oral steroids despite taking beclomethasone in conventional doses of up to $400 \mu \mathrm{g}$ per day may be able to discontinue oral steroids on high dose beclomethasone. A high dose aerosol $(250 \mu \mathrm{g}$ per shot) is now available. Smith and Hodson (1938a) found that adrenal supression was only significant above a daily total dose of $2000 \mu \mathrm{g}$. Sixty-two per cent of their cases improved on high dose beclomethasone (Smith and Hodson, 1983b) and the incidence of oral candidiasis was low, suggesting that the trauma from the aerosol jet, andڤ therefore the number of puffs used, as opposed to the total dose, is the main factor in inducing candidiasis. Inhalation of steroids is, of course, also dependent on: good patient technique. The rotahaler is effective in improving inhalation of beclomethasone (Car $-\frac{7}{7}$ michael et al., 1978) and a spacer tube is available for inhalation of budesonide (Astra).

In contrast to the increased use of inhalationa $\frac{{ }^{2}}{{ }^{2}}$ therapy, there is little logic for the dramatic increase in prescribing of sustained release preparations of theophylline and aminophylline. There is no evi- $\overrightarrow{0}$ dence that they are more effective than inhaledsympathomimetics and they are definitely not as safe. $\vec{\omega}$ The pharmacokinetics vary considerably in differen 5 patients and the threshold between therapeutic effecto and toxicity is small (Greening et al., 1981). They can only be used safely and effectively by monitoringo blood levels, but this technique is not readily available in Great Britain at present (Henne et al., 1972). The problem is illustrated by a study ais Brompton (Woodcock, Johnson and Geddes, 1983) which showed a fivefold increase in prescribing of these drugs in the last 5 years, and that $49 \%$ of cases were found to have sub-therapeutic blood levels anow $8 \%$ had toxic levels; three of these patients sustained cardiac arrest in hospital. Nevertheless, the incidence of gastrointestinal side effects was equal in patientsanno the sub-therapeutic and therapeutic ranges. I therefore believe that these drugs should be considered second line agents for areas where they have reats advantages. These are in the treatment of smalb children who can not use aerosols, in a few adults as steroid sparing treatment after a careful trial of inhaled steroids, and in some cases of nocturnat asthma.

The circadian concept in drug treatment of asthma

Recognition of the extent to which some patients asthma varies over the $24 \mathrm{hr}$ and the relationships between the amplitude of variation and the degree ope bronchial lability requires the clinician to review his approach to drugs and the ways in which he uses them. Drug trials are mostly based on the degree of overall improvement in lung function tests which is? achieved, but it is clear that the ideal drug shoulds reduce the degree of circadian fall in PEFR at night as well as raising the highest readings during the day? No currently available drug appears to fully satisfy both criteria. The problem is often illustrated by the PEFR chart of patients recovering from a severe asthma attack which has required treatment with steroids. As the attack resolves and PEFR rises, 黑 considerable increase in circadian variation is alsof seen and, during this period, there may be an increased risk of sudden death (Hetzel et al., 1977a)

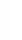


Treatment of nocturnal asthma can be very difficult. Some mild asthmatics may present with nocturnal wheezing as a prominent symptom but this disappears on treatment with regular inhalation of cromoglycate, beta ${ }_{2}$ stimulants and beclomethasone dipropionate, depending on severity. In these cases it appears that the bronchial lability manifested by the nocturnal symptoms is easily controlled by regular therapy during the day. At the other end of the spectrum, however, there are patients who have had severe nocturnal attacks for years and are refractory to treatment. One might reasonably believe that they are a high risk group, but this is not yet proven. These patients are often given slow release preparations of salbutamol or theophyllines at night, neither of which are very effective in severe cases (Fairfax et al., 1980). Comparison of treatment with aerosol salbutamol and slow release aminophylline (Penketh et al., 1981) suggests that choice of drug is less important than dosage, but some patients cannot be controlled at dosages which they can tolerate. Prior et al. (1982) have, however, claimed good results for high dose aerosol terbutaline. Barnes et al. (1982) have found that the toxicity of slow release theophyllines is better tolerated at night. This may be partly due to the fact that these drugs are better tolerated in the supine posture (Warren et al., 1983), although the mechanism of this postural effect is not fully understood. Further studies of the relative merits of high dose inhalational therapy and slow release xanthine or beta $a_{2}$ stimulant oral preparations are in progress, but it seems likely that a completely different approach will be needed to solve this problem.

Circadian considerations are also important in treatment with oral corticosteroids. While alternate day treatment is ideal for prevention of adrenal suppression, not all patients can tolerate the off treatment days. It has now been recognized, however, that, even if treatment is given every day, adrenal suppression is predominantly related to the time of day at which steroids are given, maximum suppression occurring when they are given at night. A recent study has confirmed that daily treatment in the morning is almost as good as alternate day therapy in reducing adrenal suppression; thus steroids should not be given in divided doses (McAllister et al., 1983).

\section{Conclusions}

This article has attempted to illustrate the scope for improving the care of asthma patients through the simple expedients of careful monitoring with simple lung function tests and a more logical approach to drug therapy. These simple messages have yet to be learned by many doctors, as is seen by the consistent trend in results of studies of asthma mortality
(Cochrane and Clark, 1975; Ormerod and Stableforth, 1980; BTA, 1982). These show that the two most serious errors made by doctors looking after asthmatic patients who die are failure to assess the severity of the attack by measuring PEFR and failure to use adequate treatment, especially corticosteroids, soon enough.

\section{References}

Anderson, P.B., Goude, A. \& Peake, M. (1982) Comparison of salbutamol given by intermittent positive pressure breathing and pressure packed aerosol in chronic asthma. Thorax, 37, 612 .

ASSEM, E.S.K. \& SCHILD, M.O. (1969) Inhibition by sympathomimetic amines of histamine release induced by antigen in passively sensitised human lung. Nature, 224, 1028.

Barnes, P., Fitzgerald, G., Brown, M. \& Dollery, C. (1980) Nocturnal asthma and changes in circulating epinephrine, histamine and cortisol. New England Journal of Medicine, 303, 263.

Barnes, P.J., Neville, L., Greening, A.P., Timmers, J. \& Polle, G.N. (1982) Single dose slow release aminophylline at night prevents nocturnal asthma. Lancet, i, 229.

Bateman, J.R.M., Pavia, D. \& Clarke, S.W. (1978a) The retention of lung secretions during the night in normal subjects. Clinical Science and Molecular Medicine, 55, 523.

Bateman, J.R.M., Pavia, S.W., Pavia, D. \& Sheahan, N.F. (1978b) Reduction in clearance of secretions from the human lung during sleep. Journal of Physiology, 284, 55P.

BATEMAN, J.R.M. \& CLARKE, S.W. (1979) Sudden deaths in asthma. Thorax, 34, 40.

BLOOMFIELD, P., WinSEY, N.J.P. \& CRoMPTON, G.K. (1979) A tube spacer to improve inhalation of drugs from pressurised aerosols. British Medical Journal, 2, 1479.

Brompton Hospital/Medical Research Council CollaboraTIVE TRIAL (1972) Long term study of disodium cromoglycate in treatment of severe extrinsic or intrinsic bronchial asthma in adults. British Medical Journal, 4, 383.

BRITISH THORACIC AND TUberculosis Association (1976) A controlled trial of inhaled corticosteroids in patients receiving prednisone tablets for asthma. British Journal of Diseases of the Chest, 70, 95.

BRITISH THORACIC ASSOCIATION (1982) Death from asthma in two regions of England. British Medical Journal, 285, 1251.

Burge, P.S., O'Brien, I.M. \& Harries, M.G. (1979) Peak flow records in the diagnosis of occupational asthma due to isocyanates. Thorax, 34, 317.

CARMichael, J., DUNCAN, D. \& Crompton, G.K. (1978) Beclomethasone dipropionate dry powder inhalation compared with conventional aerosol in chronic asthma. British Medical Journal, 2, 657.

ChEN, W.Y. \& Chal, H. (1982) Airway cooling and nocturnal asthma. Chest, 81, 675.

CLARK, T.J.H. (1971) The status of bronchodilator treatment. Postgraduate Medical Journal, 47 (Suppl. Feb.), 50.

CLARK, T.J.H. \& HETZEL, M.R. (1977) Diurnal variation of asthma. British Journal of Diseases of the Chest, 71, 87.

Coady, T.J., STEWART, C.J. \& DavieS, H.J. (1976a) Synchronisation of bronchodilator release. Practitioner, 217, 273.

COADY, T.J., DAVIES, H.J. \& BARNES, P. (1976b) Evaluation of a breath actuated pressurised aerosol. Clinical Allergy, 6, 1.

Cochrane, G.M. \& ClaRK, T.J.H. (1975) A survey of asthma mortality in patients between ages 35 and 64 in the Greater London Hospitals in 1971. Thorax, 30, 300.

ConNellan, S.J.B. \& WILSON, R.S.E. (1978) Nebulised salbutamol in adult asthma. Lancet, $\mathrm{i}, 662$.

CONNOLLY, C.K. (1979) Diurnal rhythms in airway obstruction. British Journal of Diseases of the Chest, 73, 357.

DAVIES, R.J., GreEN, M. \& SCHOFIELD, N.M.C. (1976) Recurrent 
nocturnal asthma after exposure to grain dust. American Review of Respiratory Disease, 114, 1011.

DAWKINS, K.D. \& MUERS, M. (1981) Diurnal variation in airflow obstruction in chronic bronchitics. Thorax. 36, 618 .

De VRIES, K., Gool, J.Y., BooY-NoRd, H. \& OrIE, N.G.M. (1962) Changes during 24 hours in the lung function and histamine hyperactivity of the bronchial tree in asthmatic and bronchitic patients. Internal Archives of Allergy, 20, 93.

Duncan, D., Patterson, I.C., Harris, D. \& Crompton, G.K. (1977) Comparison of the bronchodilator effects of salbutamol inhaled as a dry powder and by conventional pressurised aerosol. British Journal of Clinical Pharmacology, 4, 669.

EDITORIAL (1975) Management of acute asthma. British Medical Journal, 4, 65.

EDITORIAL (1981a) The pulmonary clock. Thorax, 36, 481.

EDITORIAL (1981b) Compensating occupational asthma. Thorax, 36, 881.

EDITORIAL (1982) Leukotrienes and lung disease. Thorax, 37, 241

Fairfax, A.J., Mc NabB, W.R., Davies, H.J. \& SPIRo, S. (1980) Slow release oral salbutamol and aminophylline in nocturnal asthma. Thorax, 35, 526 .

FRASER, P.M., SPEIZER, F.E., WATERS, S.D.M., Doll, R. \& MANN, N.M. (1971) The circumstances preceding death from asthma in young people in 1968 to 1969. British Journal of Diseases of the Chest, 65, 71 .

Gervais, P., Reinberg, A., Gervais, C., Smolensky, M. \& De FRANCE, O. (1977) Twenty four hour rhythm in the bronchial reactivity to house dust in asthmatics. Journal of Allergy and Clinical Immunology, 59, 20.

GODDEN, D.J. \& CROMPTON, G.K. (1981) An objective assessment of the tube spacer in patients unable to use a conventional pressurised aerosol effectively. British Journal of Diseases of the Chest, 75, 165.

GRANT, I.W.B. (1968) Deaths from asthma. British Medical Journal, $1,575$.

Greening, A.P., Baillie, E., Gribiin, H.R. \& Pride, N.B. (1981) Sustained release oral theophylline in patients with airflow obstruction. Thorax, 36, 303.

HenNe, J.W., WyZe, E., Rood, F.S. \& Macdonald, F.M. (1972) Pharmacokinetics of theophylline. Clinical Pharmacology and Therapeutics, 13, 349.

HeTZel, M.R. \& ClaRK, T.J.H. (1976) Comparison of intravenous and aerosol salbutamol. British Medical Journal, 2, 919

Hetzel, M.R., Clark, T.J.H. \& Branthwaite, M.A. (1977a) Asthma; analysis of sudden deaths and ventilatory arrests in hospital. British Medical Journal, 1, 808.

Hetzel, M.R., Batten, J.C. \& Clark, T.J.H. (1977b) Do sympathomimetic amines prevent exercise induced asthma by bronchodilatation alone? British Journal of Diseases of the Chest, 71, 109.

Hetzel, M.R. \& ClaRK, T.J.H. (1977) Comparison of salbutamol rotahaler with conventional pressurised aerosol. Clinical Allergy, 7, 563 .

HeTZEL, M.R. \& ClaRK, T.J.H. (1979a) Does sleep cause nocturnal asthma? Thorax, 34, 749 .

HeTZEL, M.R. \& ClaRK, T.J.H. (1979b) The clinical importance of circadian factors in severe asthma. In: Chronopharmacology. (Eds. A. Reinberg and F. Halberg), p. 213. Pergamon, Oxford.

Hetzel, M.R., Williams, I.P. \& Shakespeare, R.M. (1979) Can patients record peak flow rate reliably? Lancet, i, 587.

HETZEL, M.R. \& ClARK, T.J.H. (1980) Comparison of normal and asthmatic rhythms in peak expiratory flow rate. Thorax, 35, 732.

INMAN, W.H.W. \& ADELSTEIN, A.M. (1969) Rise and fall of asthma mortality in England and Wales in relation to use of pressurised aerosols. Lancet, ii, 279.

Johnston, I.D.A., ANDerson, H.R. \& Patel, S. (1983) Peak flow patterns in wheezy children. Thorax, 38, 230.

Kales, A., Beall, G.N., Bajor, G.F., Jacobson, A. \& Kales, J.D. (1968) Sleep studies in asthmatic adults. Journal of Allergy, 41, 164.
LAENNEC, R.T.H. (1827) A treatise on diseases of the chest and on mediate auscultation. (Translated Forbes) Underwood, London. $\$ MC Allister, W.A.C., HeTzel, M.R., EMERY, P., GothaM, C.R. \& CoLLINS, J.V. (1983) Comparison of efficacy and adrenal suppres sion produced by alternate day, daily and twice daily prednisone regimes for chronic asthma. Thorax, 38, 239.

Mitchell, D.M., Collins, J.V. \& MORLEY, J. (1980) An evaluation of cusum analysis in asthma. British Journal of Diseases of the Chest, 74, 169.

MOREN, F. (1978) Airway deposition of pressurised inhaled aerosols Influence of actuator tube design. International Journal of Pharmaceutics, 1, 205.

MUNTNER, S. (1963) Moses Maimonides' Treatise on Asthmad Translation. Lippincott.

Neuman, S.P., Pavia, D., Sheahan, N.F., Moren, F. \& Clarke $\vec{\circ}$ S.W. (1980) Deposition of pressurised aerosols in the lung using radio labelled particles. Thorax, 35, 234.

Newman Taylor, A.J., Davies, R.J., Hendrick, D.J. \& PePys, Jo (1979) Recurrent nocturnal asthmatic reaction to bronchiag provocation tests. Clinical Allergy, 9, 213.

NORTHERN GENERAL HOSPITAL/Brompton HosPital/MEdicaE RESEARCH Council Collaborative Trial (1976) Sodium cro moglycate in chronic asthma. British Medical Journal, 1, 361.

ORMEROD, L.P. \& STABLEFORTH, D.E. (1980) Asthma mortality in Birmingham 1975-7; 53 deaths. British Medical Journal, 280, 687

Patterson, J.W., Sudlow, M.F. \& Walker, S.R. (1971) Bloof levels of fluorinated hydrocarbons in asthmatic patients afteo inhalation of pressurised aerosols. Lancet, ii, 565 .

PATTERSON, I.C. \& CROMPTON, G.K. (1976) Use of pressurised aerosols by asthmatic patients. British Medical Journal, 1, 76.

Penketh, A.R.L., Johnson, D., Hetzel, M.R., Clark, T.J.H. Bellamy, D. \& Cochrane, G.M. (1981) Aerosol salbutamot versus slow release aminophylline in the treatment of nocturnat asthma. Thorax, 36, 715 .

Prior, J.G., Nowell, R.V. \& Cochrane, G.M. (1982) High ofse inhaled terbutaline in the management of chronic severe asth Thorax, 37, 300.

Reinberg, A., Gervais, P., Frambourg, J.C., Halberg, F. AbulKer, C., Vignaud, D. \& Dupont, J. (1970) Rhythmeso circadiens de fonctions respiratoires et de la temperature de asthmatiques sejournant en millieu hypoallergenique. Pressè Medicale, 78, 1817.

Reinberg, A., Gervais, P., Morin, M. \& Abulker, C. (1974 $\overrightarrow{\vec{D}}$ Circadian rhythm in the threshold of bronchial response to acetylcholine in healthy and asthmatic subjects. In: Chronobio logy. (Eds. L. E. Scheving, F. Halberg and J. E. Pauly), p. 174 Tokyo, Igaku Shoin.

Rubinfeld, A.R. \& PaIN, M.C.F. (1976) Perception of asthma? Lancet, i, 882.

Ryan, G., Latimer, K.M., Dolovich, J. \& Hargreaves, F.eO (1982) Bronchial responsiveness to histamine; relationship to. diurnal variation of peak flow rate, improvement after bronchodif lator and airway calibre. Thorax, 37, 423

SAUNDERS, K.B. (1965) Misuse of inhaled bronchodilator drugs. British Medical Journal, 1, 1037.

ShePherd, G.L., HeTZel, M.R. \& ClaRK, T.J.H. (1981) Regula versus symptomatic aerosol bronchodilator treatment of asthmo British Journal of Diseases of the Chest, 75, 215.

Silverman, M., ConNolly, N.M., Balfour-LynN, L. \& God N FREY, S. (1972) Long term trial of disodium cromoglycate and isoprenaline in children with asthma. British Medical Journal, 3 378.

SMITH, M.J. \& Hodson, M. (1983a) Effects of long term high dose becotide on adrenal function. Thorax, 38, 237.

SMITH, M.J. \& HodSON, M.E. (1983b) High dose beclomethasone if the treatment of asthma. Thorax, 38, 237.

Soutar, C.A., Costello, J., IJAduola, O. \& TURner-Warwick M. (1975) Nocturnal and morning asthma: relationship to plasmar corticosteroids and response to cortisol infusion. Thorax, 30, 43\% 
Soutar, C.A., Carruthers, M. \& Pickering, C.A. (1977) Nocturnal asthma and urinary adrenaline and noradrenaline secretion. Thorax, 32, 677.

Speizer, F.E., Doll, R., Heaf, P. \& Strang, L.B. (1968) Investigation into use of drugs preceding death from asthma. British Medical Journal, 1, 339.

SpIRO, S.G., MAY, C.S., Johnson, A.J. \& PATterson, J.W. (1975) Intravenous injection of salbutamol in the management of asthma. Thorax, 30, 236.

STARK, J. (1972) Status asthmaticus. British Journal of Hospital Medicine, 8, 241.

Stokes, T.C. \& MORLEY, J. (1981) Prospects for an oral Intal. British Journal of Diseases of the Chest, 75, 1.

Strauss, R.H., MC FAdDEN, E.R., IngRam, R.H. \& JAEger, J. (1977) Enhancement of exercise induced asthma by cold air. New England Journal of Medicine, $297,743$.

TURNER-WARWICK, M. (1977) On observing patterns of airflow obstruction in chronic asthma. British Journal of Diseases of the Chest, 71, 73.
Trousseau, A. (1868) Lectures on clinical medicine. (Translated Barzine, V.) London, New Sydenham Society.

Venables, K.M., Burge, P.S., Davison, A.G. \& NewmanTAYLOR, A.J. (1983) Are PEFR records a reliable way of diagnosing asthma? Thorax, 38, 238.

Walker, S.R., Evans, M.E., Richards, A.J. \& Patterson, J.W. (1972) The clinical pharmacology of oral and inhaled salbutamol. Clinical Pharmacology and Therapeutics, 13, 861.

Warren, J.B., Turner, C., Dalton, N., Thompson, A., CoCHRANE, G.M. \& ClaRK, T.J.H. (1983) Effect of posture on the sympatho-adrenal response to theophylline infusion. Thorax, 38 , 239.

WiLlis, T. (1679) Pharmacutiae Rationalis. 2nd part. London, Dring, Harper and Leigh.

WoodCock, A.A., JoHNSON, M.A. \& GedDES, D.M. (1983) Theophylline prescribing, serum levels and toxicity. Thorax, 38, 240.

WRIGHT, B.M. (1978) A miniature Wright peak flow meter. British Medical Journal, 2, 1627. 